\title{
Is FAM19A5 an adipokine? Peripheral FAM19A5 in wild-type, FAM19A5 knock-out, and LacZ knock-in mice
}

Hoyun Kwak ${ }^{1 \S}$, Eun-Ho Cho ${ }^{1 \S}$, Eun Bee Cho ${ }^{1}$, Yoo-Na Lee ${ }^{2}$, Anu Shahapal ${ }^{2}$, Hyo Jeong Yong ${ }^{2}$, Arfaxad Reyes-Alcaraz ${ }^{3}$, Yongwoo Jeong ${ }^{1}$, Yerim Lee ${ }^{1}$, Minhyeok Lee ${ }^{1}$, Nui Ha ${ }^{1}$, Sitaek Oh ${ }^{1}$, Jae Keun Lee ${ }^{1}$, Won Suk Lee ${ }^{1}$, Wonkyum Kim ${ }^{1}$, Jong-Ik Hwang ${ }^{2}$, and Jae Young Seong ${ }^{2 *}$

${ }^{1}$ Neuracle Science Co. Ltd., Seoul 02841, Republic of Korea

${ }^{2}$ Graduate School of Biomedical Sciences, Korea University College of Medicine, Seoul 02841, Republic of Korea

${ }^{3}$ College of Pharmacy, University of Houston, Texas, United States of America

${ }^{\S}$ H.K. and E-HC contributed equally to this work.

\section{*Correspondence:}

Jae Young Seong, Ph. D

Graduate School of Biomedical Sciences, Korea University College of Medicine, Seoul 02841, Republic of Korea

Tel: +82-2-2286-1090; Fax: +82-2-921-4355

jyseong@korea.ac.kr

Short title: FAM19A5 in peripheral tissues

Keywords: FAM19A5, peripheral expression, brain, adipose tissue, qRT-PCR, ELISA, Western blot

\begin{abstract}
FAM19A5 (also called TAFA5) is a novel secretory protein that is primarily expressed in the brain. However, a recent study reported that FAM19A5 is an adipocyte-derived adipokine that regulates vascular smooth muscle function. Furthermore, genome-wide association study (GWAS) and RNA-seq analyses revealed that the FAM19A5 was associated with a variety of diseases and tumorigenesis in peripheral tissues. We investigated FAM19A5 transcript and protein levels in the
\end{abstract}


peripheral tissues, including adipose tissues from wild-type, FAM19A5 knock-out, and LacZ knock-in mice. In general, total FAM19A5 transcript levels in the central and peripheral nervous systems were higher than levels in any of the peripheral tissues including adipose tissues. Brain tissues expressed similar levels of the FAM19A5 transcript isoforms 1 and 2, whereas expression in the peripheral tissues predominantly expressed isoform 2. In the peripheral tissues, but not the brain, FAM19A5 protein levels in adipose and reproductive tissues were below detectable limits for analysis by Western blot. Additionally, we found that FAM19A5 protein did not interact with the S1PR2 receptor for G-protein-mediated signal transduction, $\beta$-arrestin recruitment, and ligandmediated internalization. Instead, FAM19A5 was internalized into HEK293 cells in an extracellular matrix protein-dependent manner. Taken together, the present study determined basal levels of FAM19A5 transcripts and proteins in peripheral tissues, which provides compelling evidence to further investigate the function of FAM19A5 in peripheral tissues under pathological conditions, including metabolic diseases and/or tumorigenesis.

\section{Introduction}

Family with sequence similarity 19 member A5 (FAM19A5, also named TAFA5) is a member of the FAM19A protein family, which is highly expressed in the brain ${ }^{1}$. The FAM19A5 gene encodes a secretory protein that has a high degree of amino acid sequence identity across vertebrate species ${ }^{2}$, suggesting functional relevance in vertebrates. Both human and mouse FAM19A5 genes can produce two forms of the transcript, known as isoform 1 and isoform 2, due to the alternative use of the first exon, exon1-1 and exon1-2. As a result, the two FAM19A5 isoform proteins differ in their $\mathrm{N}$-terminal sequences. Isoform 1 produces a precursor protein that is cleaved at the end of the signal peptide to generate a mature, secreted, 89 amino acid protein ${ }^{3}$. Isoform 2, however, can have two different fates. Isoform 2 may generate a protein that associates with the plasma membrane due to a hydrophobic $\alpha$-helix at the $\mathrm{N}$-terminus ${ }^{4}$. Alternatively, the $\mathrm{N}$ terminal sequence can also serve as a signal peptide, resulting in a secreted protein that is identical to the mature protein produced by isoform $1^{3}$.

Transcripts for the FAM19A5 gene are abundant in the brain and comparatively sparse in the peripheral tissues ${ }^{1}$. Recently, using FAM19A5-LacZ knock-in (KI) mice, we determined the expression patterns of FAM19A5 during embryogenesis and in the adult brain. We also identified specific cell types in the brain that expressed FAM19A5 $5^{5}$ FAM19A5 was expressed in the ventricular zone and the ganglionic eminence during a very early stage of brain development. These expression patterns suggest that the function of FAM19A5 is related to the proliferation and differentiation of neural stem cells and oligodendrocyte precursor cells (OPCs) ${ }^{5}$. In the adult brain, X-gal staining combined with immunostaining for cell-type markers revealed that FAM19A5 was expressed in diverse cell types, including neurons, astrocytes, OPCs, and microglia ${ }^{5}$. The expression of FAM19A5 in diverse cell types was consistent with results from single-cell RNA- 
sequencing of mouse and human brains ${ }^{6,7}$. Notably, after traumatic brain injury, FAM19A5 expression is significantly elevated in a subset of neuronal populations in the injury penumbra of the cortex and in some OPCs in the corpus callosum ${ }^{5}$, indicating that FAM19A5 contributes to the wound healing process after brain injury.

In addition to its importance in the brain, recent studies suggest that FAM19A5 also has a role in peripheral tissues. FAM19A5 is reported to be involved in the RANKL-induced differentiation of osteoclast precursor cells through interactions with formyl peptide receptor $2^{8}$. Another study showed that FAM19A5 suppressed neointima formation in injured rat carotid arteries by interacting with the sphingosine-1-phosphate receptor 2 (S1PR2) ${ }^{3}$. In this study, FAM19A5 is primarily produced in adipose tissue. Analysis of human tissue samples by qRTPCR revealed that FAM19A5 mRNA levels in adipose tissues are higher than brain tissue levels. Furthermore, immunohistochemistry and enzyme-linked immunosorbent assays (ELISAs) for FAM19A5 have shown high levels of FAM19A5 protein in human and rodent adipose tissues ${ }^{3}$. Intriguingly, FAM19A5 mRNA and protein levels are significantly down-regulated in obese and diabetic animals ${ }^{3}$, suggesting a causal relationship between decreased FAM19A5 levels and metabolic disease conditions. However, this result is in part contradictory to a recent observation in humans where individuals with type 2 diabetes had higher FAM19A5 serum levels than those without type 2 diabetes ${ }^{9}$. The public database for human tissue RNA expression reports that FAM19A5 is expressed in the female and male reproductive tissues including the ovaries, uterus, and testis, although absolute levels in these tissues are significantly lower than brain tissue levels ${ }^{4,10}$.

The open-targets-platform (https://www.targetvalidation.org/) database shows that 47 human diseases are associated with the FAM19A5 gene including Alzheimer's ${ }^{11,12}$, schizophrenia $^{13,14}$, bipolar disorder ${ }^{15}$, pancreatic carcinoma ${ }^{16}$, and endometrial neoplasm ${ }^{17}$, among others $^{18}$. Interestingly, the mosaic monosomy of chromosome 22, which includes disruption of the FAM19A5 gene, leads to skeletal abnormalities, low body weight, and neuropsychiatric conditions, including attention deficit hyperactivity disorder, aggression, and autistic symptoms ${ }^{19}$. Recently, the deletion of chromosome 22q13.32, including the FAM19A5 gene, was associated with schizencephaly accompanied by occipital encephalocele ${ }^{20}$. Multiple copies of the FAM19A5 gene have been associated with glioma ${ }^{21}$. Consistent with this finding, FAM19A5 transcript levels are elevated in patients with glioma, pancreatic cancer, and melanoma ${ }^{22}$. Similarly, the Genomic Data Commons (GDC) Data Portal database from the National Cancer Institute (https://portal.gdc.cancer.gov/) lists FAM19A5 mutations in several types of cancer including adenocarcinoma and squamous neoplasia, and in multiple cancer sites including the corpus or cervix uteri, colon, bronchus, and lungs ${ }^{23}$.

The association of FAM19A5 with several disease states has increased the urgency to measure and understand its expression in a variety of peripheral tissues. In the present study, we examined basal levels of FAM19A5 transcripts and proteins in a variety of peripheral tissues using 
qRT-PCR and Western blotting. The methods were verified with FAM19A5 knock-out (KO) mice. We also identified the cell types that express FAM19A5 with X-gal staining of peripheral tissues from FAM19A5-LacZ knock-in (KI) mice, as previously described ${ }^{5}$. In contrast to previous report ${ }^{3}$, this study also demonstrated that FAM19A5 transcript and protein levels in adipose tissues are very low compared to those in the brain tissues and that S1PR2 does not interact with FAM19A5 protein for receptor-mediated signal transduction, $\beta$-arrestin recruitment, and ligand-mediated receptor internalization.

\section{Methods}

\section{Animals}

C57BL/6J mice were purchased from Nara Biotech (Seoul, Korea) or Orient Bio, Inc. (Seongnam, Korea). Mice were housed in temperature-controlled $\left(22-23^{\circ} \mathrm{C}\right)$ conditions with a 12 $\mathrm{h}$ light/12-h dark light cycle. The mice were given ad libitum standard chow and water. All animal experiments were designed to use the fewest mice possible and anesthesia was administered, when necessary. All animal procedures were approved by the Institutional Animal Care and Use Committee of Korea University (KOREA-2019-0076 and KOREA-2019-0032).

\section{Generation of FAM19A5 knock-out (KO) mice}

FAM19A5 KO mice were generated by ToolGen, Inc. (Seoul, Korea) using the CRISPR/Cas9 system ${ }^{24}$. Briefly, single-guide RNAs (sgRNAs) were designed to target a 5'-UTR sequence of exon 1 (left sgRNA, CCGTCTCTGTCGCCATCCAGAGG E1-1) and the 3'-UTR sequence of exon 4 (right sgRNA, CTTGGCACTTAACTCCCAGATGG). Cas9 mRNA and sgRNAs were microinjected into the cytoplasm of C57BL/6J mice zygotes, and the resulting embryos were transferred into the oviducts of IcrTac:ICR pseudo-pregnant foster mothers to produce live founder mice. Founder mice with mutant alleles were screened using genomic DNA PCR to amplify the genomic region spanning the sgRNA target sites. The primer sequences for the founder screening PCR were: Forward, GGGGGTCCCAAGTCACCTAAC, and Reverse, AAGAACTTGGGAGACAGGCAAA. The PCR products from the founder mice were cloned and the corresponding mutations were identified by direct-sequencing analysis (Bionics Co., Ltd., Seoul, Korea). Founder mice with a mutant allele that lacked the $125,000 \mathrm{bp}$ sequence containing exon 1 to exon 4 were bred with wild-type mice. Germline transmission of the mutant allele was determined by genotyping with the following primers: gF1, TCGGTTCACTTTCCGGATCAAT; gR1, AAGAACTTGGGAGACAGGCAAA; gF2, TCCTGGGAGAGGGGAATAGTTT. Homozygous FAM19A5 knock-out (KO) mice were generated by heterozygous intercross breeding. 


\section{FAM19A5-LacZ knock-in (KI) mice}

FAM19A5-LacZ KI mice were generated by the UC Davis Mouse Biology Program as previously described ${ }^{5}$. The gene-trap method using $L a c Z$ as a reporter gene was employed to visualize FAM19A5 expression in tissue sections ${ }^{25}$. Briefly, the target vector containing the IRESlacZ gene was inserted in front of exon 4 of the FAM19A5 gene. The LacZ gene is expressed independently of the target FAM19A5 gene due to an IRES element. This FAM19A5-targeting vector was delivered to embryonic stem cells by electroporation. We confirmed vector incorporation into the target chromosome by genotyping and chromosome counting of transgenic embryonic stem cells. Selected transgenic embryonic stem cells were injected into blastocysts, and the embryos were implanted into the uterus of female recipient mice. We performed a germline transmission test to check for stable germline expression in the chimeric generation. The generated FAM19A5-LacZ KI chimeric mice were backcrossed onto a C57BL/6J genetic background.

\section{Quantitative real-time polymerase chain reaction (qRT-PCR) analysis}

TRIzol reagent (Invitrogen, USA) was used to isolate total RNA from mouse tissues. The analyzed tissues included the cerebral cortex, hippocampus, spinal cord, heart, aorta, kidney, lung, stomach, small intestine, large intestine, pancreas, liver, salivary gland, thymus, spleen, bone marrow, adrenal gland, pituitary gland, thyroid gland, skeletal muscle, white adipose, brown adipose, and skin. One microgram of RNA was reverse-transcribed into complementary DNA with the RevertAid First Strand cDNA Synthesis kit (Thermo Fisher Scientific, USA). The primer sequences used for qRT-PCR were as follows: mFAM19A5-Iso1-F, 5'- GTC CTC AAC TTT TTG GGC ATT C -3'; mFAM19A5-Iso2-F, 5'- GCG ATG CAG CTC CTG AAG -3'; mFAM19A5Iso1,2-R, 5'- CCC GGT CTA GGG TCA CAA -3'; mFAM19A5-Total-F, 5'- GGC AGA TAG CAG GCA CCA CT -3'; mFAM19A5-Total-R, 5'- GCT GCG ATT GTC AGG AGA CC -3'; mGAPDH-F, 5'- ATC CTG CAC CAC CAA CTG CT -3'; mGAPDH-R, 5'- GGG CCA TCC ACA GTC TTC TG -3'. The CFX96 Touch RT-PCR detection system using SsoAdvanced Universal SYBR Green Supermix (Bio-Rad, USA) was used for qRT-PCR. Gene expression was normalized to GAPDH levels, and the relative quantity of mRNA was calculated using the comparative $\mathrm{Cq}$ method.

\section{X-gal staining}

X-gal staining was performed as previously described ${ }^{5}$ using 10-week-old adult wild-type (WT) littermates (2 males) and FAM19A5-LacZ KI heterozygote (1 male) and homozygote (3 males and 1 female) mice. Mice were perfused with normal saline and $4 \%$ paraformaldehyde in $1 \times$ phosphate-buffered saline (PBS). Subsequently, brain and peripheral tissues were isolated, 
fixed in $4 \%$ paraformaldehyde for $3 \mathrm{~h}$ at $4{ }^{\circ} \mathrm{C}$ and cryoprotected with $30 \%$ sucrose in $1 \times$ PBS for $36 \mathrm{~h}$ at $4^{\circ} \mathrm{C}$. The cryoprotected tissues were embedded with optimal compound temperature (OCT) and a 30\% sucrose compound (2:3 ratio). The embedded blocks were sectioned at $20 \mu \mathrm{m}$ using a cryostat (Leica, Wetzlar, Germany). Cryosections that were mounted on glass slides were washed twice with $1 \times$ PBS for 5 min each, permeabilized with $0.01 \%$ sodium deoxycholate and $0.02 \%$ Igepal CA-630 in $1 \times \mathrm{PBS}$ for $15 \mathrm{~min}$ and incubated in an X-gal solution for $24 \mathrm{~h}$ at $37^{\circ} \mathrm{C}$ in the dark. The X-gal solution contained $1 \mathrm{mg} / \mathrm{ml}$ of X-gal, $2 \mathrm{mM}$ magnesium chloride, $5 \mathrm{mM}$ ethylene glycol-bis (2-aminoethylether)-N,N,N',N'-tetraacetic acid, $5 \mathrm{mM}$ potassium ferrocyanide, $5 \mathrm{mM}$ potassium ferricyanide, $0.01 \%$ sodium deoxycholate, and $0.02 \%$ Igepal CA-630 in $0.1 \mathrm{M}$ phosphate buffer (PB) at $\mathrm{pH}$ 7.4. X-gal-stained sections were washed twice with $1 \mathrm{X}$ PBS for 5 min each, counter-stained with Mayer's hematoxylin, dehydrated with graded ethanol and xylene, and mounted with a cover glass.

The tissue-specific X-gal signal was scored according to the following criteria: No X-gal signal in either WT or FAM19A5-LacZ KI mice was indicated by “-”. A non-specific X-gal signal detected in both WT and FAM19A5-LacZ KI mice, which was likely due to endogenous $\beta$-gal, was represented by " $\triangle$ ". An ambiguous signal in both WT and FAM19A5-LacZ KI mice was indicated by " $\Delta /+$ ". Ambiguity was defined as a signal in FAM19A5-LacZ KI mice that appeared stronger than the signal in WT mice or a negligible signal that was only found in FAM19A5-LacZ KI mice. A positive signal observed only in FAM19A5-LacZ KI mice, but not in WT mice was denoted by "+". Among the samples with a positive signal, " $1+$ " indicated a faint positive signal with sparse, cellular blue precipitate, " $2+$ " indicated a weak positive signal with one or more blue precipitate areas per cell, " $3+$ " indicated a moderate positive signal that was observed in many cells, and " $>4+"$ indicated a robust positive signal.

\section{Purification and fluorescence labeling of FAM19A5 protein}

Recombinant N-terminal His-tagged FAM19A5 (N-HIS-FAM19A5) with a tobacco etch virus protease recognition sequence was cloned into the vector pCAG1.1 and expressed in Expi293F cells. The supernatant of the transfected cells encoding for N-HIS-FAM19A5 was collected for Ni-NTA affinity chromatography (Qiagen, Germany). Purified N-HIS-FAM19A5 was then digested overnight at $30^{\circ} \mathrm{C}$ with AcTEV protease (Thermo Fisher Scientific, USA) to remove the His-tag. Following the cleavage reaction, the digestion products were verified by SDSPAGE and Western blotting analysis. Purified FAM19A5 was used as a Western blotting control. Next, the purified FAM19A5 was labeled with Alexa Fluor 488 or Cy3 using a protein labeling kit (Expedeon, United Kingdom), according to the manufacturer's instructions. Following the reaction, FAM19A5-Alexa 488 (A488) or the Cy3 conjugates were buffer-exchanged into phosphate-buffered saline (PBS) and concentrated using Centricon filters (Millipore, Germany). 


\section{Generation of anti-FAM19A5 antibodies}

To generate anti-FAM195 chimeric human/chicken monoclonal antibodies, chickens (Gallus gallus domesticus) were immunized with purified N-terminal His-tagged FAM19A5 protein. Total RNA was extracted from the spleen, bursa of Fabricius, and bone marrow of the immunized chickens and cDNA was synthesized. From the synthesized cDNA, a single-chain variable fragment ( $\mathrm{scFv}$ ) library was constructed with the pComb3X-SS vector system (The Scripps Research Institute, La Jolla, CA, USA). Helper phage VCM13 was added to the culture medium for phagemid DNA and phage-displayed scFv extraction. Biopanning was performed using recombinant N-His-FAM19A5-coated magnetic-beads with the phage-displayed scFv. Phage that bound by biopanning were amplified and used for a second round of biopanning. Biopanning was repeated five times and each time the number of washes was increased to identify the highest-affinity phage. ELISA was used to test randomly selected phage-displayed scFv clones from biopanning for affinity against recombinant FAM19A5. The human $\mathrm{C}_{K}$ gene was linked to the anti-FAM19A5 antibody sequence that encoded the light chain variable region, and the $\mathrm{CH} 1$, $\mathrm{CH} 2$, and $\mathrm{CH} 3$ genes of human immunoglobulin isotype IgG1 were added to the heavy chain variable region (Genscript, USA). Vectors that encoded the anti-FAM19A5-IgG1 antibody were transfected into HEK293F cells and the recombinant antibody was purified using Protein A beads (RepliGen). Anti-FAM19A5 antibodies that recognized the epitopes formed at N-terminal and Cterminal regions were generated and called $\mathrm{N}-\mathrm{A} 5-\mathrm{Ab}$ and $\mathrm{C}-\mathrm{A} 5-\mathrm{Ab}$, respectively. The purified antibodies were conjugated with HRP or Alexa 488/Cy3 using an antibody labeling kit (Expedeon, United Kingdom) according to the manufacturer's instructions.

\section{Antibody-specificity test}

HEK293T cells that were stably transfected with genes encoding for the FAM19A family of proteins were lysed in buffer containing $50 \mathrm{mM}$ Tris-HCL (pH 6.8), 2\% SDS, 10\% glycerol, $100 \mathrm{mM}$ mercaptoethanol, and bromophenol blue. Whole-cell extracts were resolved on SDSPAGE gels and transferred to prewetted PVDF blotting membranes in a Trans-Blot Turbo apparatus (Bio-Rad, USA). The blots were blocked in Tris-buffered saline containing $0.3 \%$ Tween 20 and 5\% skim milk followed by incubation with HRP-conjugated N-A5-Ab at room temperature for $3 \mathrm{~h}$. The blots were then washed three times and GE healthcare ECL reagents were applied. Immunoreactive bands were visualized by X-ray film with exposure times of 0.5 or 10 min.

\section{Western blot analysis}

Mouse brain tissue was homogenized in buffer containing $20 \mathrm{mM}$ Tris- $\mathrm{HCl}$ ( $\mathrm{pH} 7.5$ ), 500 $\mathrm{mM} \mathrm{NaCl}, 5 \mathrm{mM} \mathrm{MgCl}_{2}$, and protease inhibitor cocktail (Thermo Fisher Scientific). Protein 
quantification of the homogenized tissues was completed with the Pierce BCA Protein Assay (Thermo Fisher Scientific). Brain homogenates were then resolved on Tris-Glycine gels (Invitrogen, USA) and transferred to prewetted PVDF blotting membranes in a Trans-Blot Turbo apparatus (Bio-Rad, USA). The membrane was blocked in Tris-buffered saline containing 0.05\% Tween 20 and 5\% skim milk, followed by overnight incubation with HRP-conjugated N-A5-Ab at $4{ }^{\circ} \mathrm{C}$. The blots were then washed three times with Tris-buffered saline (TBS) containing $0.05 \%$ Tween 20. After the application of ECL reagents (Thermo Fisher Scientific), the immunoreactive bands were visualized (photographed) with a Mini HD9 (UVItec, Cambridge, UK) system using a 30-sec exposure.

\section{SRE-Luciferase assay for S1PR2 activation}

The pcDNA3.1 vector was purchased from Invitrogen (San Diego, Ca, USA). The SREluciferase (SRE-luc) vector containing a single copy of the serum response element (SRE: CCATATTAGG) conjugated to luciferase was purchased from Stratagene (La Jolla, CA, USA). The cDNAs for human S1PR2 were obtained from BRN SCIENCE, INC. The cDNA genes were inserted into the EcoRI and XhoI sites of pcDNA3.1. HEK293 cells were obtained from the American Type Culture Collection (ATCC; Manassas, VA, USA). Previously, we constructed a HEK293 cell line that stably expressed $G_{q i}$ and allowed for the induction of $G_{q}$-dependent signaling pathways upon activation of a $\mathrm{G}_{\mathrm{i}}$-coupled receptor ${ }^{26,27}$. For the luciferase assays, HEK293 $\mathrm{G}_{\mathrm{qi}}$ cells were seeded 1 day prior to transfection in 48 -well plates at a density of $2.5 \times 10^{4}$ cells per well. A mixture that included $100 \mathrm{ng}$ of SRE-luc reporter construct, $100 \mathrm{ng}$ of expression plasmid, and lipofectamine 2000 (Invitrogen, CA, USA) was diluted in Opti-MEM (Gibco) and incubated at room temperature for $20 \mathrm{~min}$. The transfection mixture was then added to the cells according to the manufacturer's instructions. Approximately 30-32 $\mathrm{h}$ post-transfection, the medium was aspirated and replaced with serum-free Dulbecco's modified Eagle's medium (DMEM) for 16-18 $h$, followed by incubation with sphingosine-1-phosphate (S1P) or purified FAM19A5 protein for $6 \mathrm{~h}$. Cells were lysed by adding $100 \mu \mathrm{l}$ of lysis buffer to the wells. Luciferase activity was determined by analyzing $50 \mu \mathrm{l}$ of each cell extract in a luciferase assay system according to the standard protocol for the Synergy 2 Multi-Mode Microplate Reader (BioTek, Winooski, VT, USA).

\section{Flow-cytometry analysis for FAM19A5 binding to HEK293 cells}

To analyze FAM19A5 binding, HEK293 cells were blocked with $1 \%$ BSA in $1 \times$ PBS for $1 \mathrm{hr}$. The blocked cells were then incubated with $2 \mu \mathrm{g}$ of FAM19A5-A488 and/or $20 \mu \mathrm{g}$ of nonlabeled FAM19A5 or fibronectin for 30 min at $4{ }^{\circ} \mathrm{C}$. FAM19A5-A488 labeled cells were detected by Guava flow-cytometry system (Luminex, Austin, TX, USA) and analyzed using the Guava software. 


\section{Confocal imaging for S1PR2 and FAM19A5 internalization}

HEK293 cells were seeded at a density of $4.5 \times 10^{4}$ cells/well on poly-L-lysine-coated plastic film coverslips in 12-well plates. The following day, the cells were transfected with S1PR2GFP plasmids (300 ng). One day post-transfection, the cells were incubated in serum-free MEM for $16 \mathrm{~h}$ prior to treatment with S1P (Sigma-Aldrich, MO, USA) and FAM19A5. Internalization of FAM19A5-A488 or FAM19A5-Cy3 $(10 \mu \mathrm{g} / \mathrm{ml})$ was also investigated in the presence of $10 \%$ serum, fibronectin $(200 \mu \mathrm{g} / \mathrm{ml})$, fibrinogen $(200 \mu \mathrm{g} / \mathrm{ml})$, and laminin $(200 \mu \mathrm{g} / \mathrm{ml})$. For inhibition of FAM19A5 internalization, cells were pretreated with one of various endocytosis inhibitors, including dynasore $(80 \mu \mathrm{M}, 30 \mathrm{~min})$, pitstop (30 $\mathrm{M}, 15 \mathrm{~min})$, chlorpromazine $(10 \mu \mathrm{g} / \mathrm{ml}, 30 \mathrm{~min})$, filipin $(5 \mu \mathrm{g} / \mathrm{ml}, 30 \mathrm{~min})$, and nystatin $(25 \mu \mathrm{g} / \mathrm{ml}, 30 \mathrm{~min})$ for the indicated time at $37^{\circ} \mathrm{C}$. Cell images were taken $30 \mathrm{~min}$ after the ligand treatment using a confocal laser scanning microscope (Leica TCS-SP8; Leica microsystems, Wetzlar, Germany).

\section{NanoLuc luciferase complementation assay}

The NanoLuc luciferase complementation assay to detect S1PR2 and $\beta$-arrestin interactions was performed as previously described ${ }^{28,29}$. Briefly, the NanoBit starter kit containing the plasmids and the necessary reagents to complete the structural complementation assays in this study were a gift from the Promega Company (Madison, Wisconsin, USA). HEK293 cells were maintained in DMEM that was supplemented with 10\% FBS, $100 \mathrm{U} / \mathrm{ml}$ penicillin $\mathrm{G}$, and 100 $\mu \mathrm{g} / \mathrm{ml}$ streptomycin (Gibco). During the experiments, the cells were tested for mycoplasma using a Universal Mycoplasma Detection kit (ATCC). One day prior to transfection, the cells were seeded in poly-L-lysine (Sigma-Aldrich, MO, USA)-coated 96-well plates at a density of $2.5 \times 10^{4}$ cells per well. A mixture containing $100 \mathrm{ng}$ of $\beta$-arrestin construct with SmBit, $100 \mathrm{ng}$ of S1PR2 with LgBit or Nluc, and $0.4 \mu 1$ of lipofectamine 2000 (Invitrogen) was prepared and added to each well. Six hours post-transfection, the medium was aspirated and replaced with serum-free DMEM. Twenty-four hours post-transfection, the medium was aspirated and replaced with $100 \mu$ of OPTIMEM (Gibco) at room temperature. After a 10-min room temperature incubation, $25 \mu 1$ of furimazine substrate was added and luminescence measurements were recorded every minute for $10 \mathrm{~min}$. Next, $10 \mu \mathrm{l}$ of ligand was added to each well and luminescence measurements were recorded immediately for $30 \mathrm{~min}$ at 1-min intervals (Synergy H1 Hybrid Multi-Mode Reader, BioTek, Winooski, VT, USA).

\section{Data analysis}

Data analyses were performed using GraphPad Prism 5 software (GraphPad software, Inc., La Jolla, CA). Data are shown as the means \pm standard errors of the mean. 


\section{Results}

\section{FAM19A5 mRNA levels in peripheral and brain tissues}

To determine FAM19A5 transcript levels, tissue samples from the central and peripheral nervous systems, including the cerebral cortex, hippocampus, spinal cord, and dorsal root ganglion, were analyzed with quantitative real-time PCR (qRT-PCR). In addition, tissue samples from the peripheral tissues, including the heart, aorta, kidney, lung, stomach, small intestine, large intestine, pancreas, liver, salivary glands, thymus, spleen, bone marrow, adrenal gland, pituitary gland, thyroid gland, skeletal muscle, adipose tissues, skin, testis, seminal vesicle, coagulating gland, uterus, and ovaries, were also analyzed by qRT-PCR. Transcript levels were detected with specific primer sets for FAM19A5 isoform 1, FAM19A5 isoform 2, and the total transcript (Figure 1A). Possible genomic DNA contamination for all tissues was assessed by performing identical PCR reactions on samples that had not been reverse transcribed and showed either no contamination or negligible levels of contamination that did not interfere with qRT-PCR. Transcript levels were compared with GAPDH levels. The FAM19A5 total transcript levels were approximately equal to the sum of the isoform 1 and isoform 2 levels (Figure 1B, C, D and Table 1).

Tissues from the central nervous system (CNS), including the cerebral cortex, hippocampus, and spinal cord, exhibited the highest levels of isoforms1/2 and total FAM19A5 transcripts. DRG, which is a representative peripheral nervous system (PNS) tissue, also exhibited high FAM19A5 transcript levels. For these CNS and PNS tissues, FAM19A5 transcript levels were not significantly different between male and female mice (Figure 1B, C, D and Table 1).

In general, peripheral tissues exhibited very low levels of FAM19A5 transcripts that ranged between $1 / 100$ to $1 / 10$ of the total transcript levels found in CNS tissues. It is also notable that isoform 1 transcripts were negligibly low in all examined peripheral tissues. In contrast, isoform 2 transcripts were moderately expressed in male and female reproductive tissues, and endocrine tissues including the thyroid, pituitary, and adrenal glands. Other tissues including white and brown adipose tissue exhibited low levels of the total transcript and isoform 2 (Figure 1B, C, D and Table 1).

Table 1. FAM19A5 expression profile of mouse peripheral tissues using qRT-PCR and X-gal staining of wildtype and FAM19A5-LacZ knock-in (+/+) mice.

\begin{tabular}{|c|c|c|c|c|c|c|c|c|c|c|}
\hline \multirow{3}{*}{ Organ systems } & \multirow{3}{*}{$\begin{array}{l}\text { Peripheral } \\
\text { tissues }\end{array}$} & \multicolumn{6}{|c|}{ FAM19A5 / GAPDH } & \multicolumn{3}{|c|}{ LacZ expression } \\
\hline & & \multicolumn{2}{|c|}{ Total } & \multicolumn{2}{|c|}{ Iso1 } & \multicolumn{2}{|c|}{ Iso2 } & \multirow{2}{*}{-Male } & \multirow{2}{*}{\multicolumn{2}{|c|}{ Female Cell type }} \\
\hline & & Male & Female & Male & Female & Male & Female & & & \\
\hline \multirow{3}{*}{ CNS } & Cortex & 976.5 & 882.9 & 348.3 & 321.2 & 460.8 & 447.0 & $>4+$ & $>4+$ & \multirow{3}{*}{ +: Neurons, glia } \\
\hline & Hippocampus & 1339.5 & 1194.3 & 694.0 & 557.1 & 480.3 & 425.5 & $>4+$ & $>4+$ & \\
\hline & Spinal cord & 906.2 & 869.4 & 385.4 & 335.6 & 575.7 & 506.6 & $>4+$ & $>4+$ & \\
\hline
\end{tabular}


bioRxiv preprint doi: https://doi.org/10.1101/2020.02.19.955351; this version posted February 20, 2020. The copyright holder for this preprint (which was not certified by peer review) is the author/funder, who has granted bioRxiv a license to display the preprint in perpetuity. It is made available under aCC-BY-ND 4.0 International IFA19A5 peripheral expression

\begin{tabular}{|c|c|c|c|c|c|c|c|c|c|c|}
\hline \multirow{3}{*}{ Organ systems } & \multirow{3}{*}{$\begin{array}{l}\text { Peripheral } \\
\text { tissues }\end{array}$} & \multicolumn{6}{|c|}{ FAM19A5 / GAPDH } & \multicolumn{3}{|c|}{ LacZ expression } \\
\hline & & \multicolumn{2}{|c|}{ Total } & \multicolumn{2}{|c|}{ Iso1 } & \multicolumn{2}{|c|}{ Iso2 } & \multirow{2}{*}{-Male } & \multirow{2}{*}{ Female } & \multirow{2}{*}{ Cell type } \\
\hline & & Male & Female & Male & Female & Male & Female & & & \\
\hline PNS & DRG & 235.8 & 224.9 & 58.9 & 58.1 & 114.7 & 218.7 & $4+$ & $4+$ & \\
\hline \multirow{2}{*}{$\begin{array}{l}\text { Cardiovascular } \\
\text { system }\end{array}$} & Heart & 21.9 & 19.2 & 0.4 & 0.3 & 24.6 & 22.9 & $2+$ & $2+$ & +: Cardiac muscle cell \\
\hline & Aorta & 13.9 & 18.0 & 0.6 & 0.2 & 22.5 & 24.5 & - & NT & - \\
\hline Urinary system & Kidney & 34.4 & 38.9 & 0.1 & 0.1 & 54.6 & 65.1 & $\begin{array}{l}\Delta ; \Delta /+ \\
\Delta /+\end{array}$ & $\begin{array}{l}\Delta ; \Delta /+ \\
\Delta /+\end{array}$ & $\begin{array}{l}\Delta: \text { Glomeruli and renal } \\
\text { tubular epithelium } \\
\Delta /+: \text { Renal tubular } \\
\text { epithelium }\end{array}$ \\
\hline $\begin{array}{l}\text { Respiratory } \\
\text { system }\end{array}$ & Lung & 28.6 & 30.9 & 1.3 & 0.9 & 43.8 & 43.8 & $\Delta$ & $\Delta$ & - \\
\hline \multirow{6}{*}{$\begin{array}{l}\text { Alimentary } \\
\text { system }\end{array}$} & Stomach & 33.3 & 30.3 & 3.9 & 3.1 & 40.6 & 36.6 & $1+; \Delta$ & $1+; \Delta$ & \multirow{3}{*}{$\begin{array}{l}+: \text { Smooth muscle } \\
\text { cell/Myenteric plexus, } \\
-\Delta: \text { Mucosal cells }\end{array}$} \\
\hline & Small intestine & 4.2 & 3.6 & 2.3 & 0.1 & 5.2 & 4.2 & $1+; \Delta$ & $1+; \Delta$ & \\
\hline & Lage intestine & 26.9 & 35.4 & 4.5 & 6.3 & 23.6 & 33.2 & $1+; \Delta$ & $1+; \Delta$ & \\
\hline & Pancreas & 34.7 & 33.4 & 4.0 & 3.5 & 40.0 & 29.2 & - & - & - \\
\hline & Liver & 8.2 & 5.7 & ND & ND & 11.4 & 8.3 & - & - & - \\
\hline & Salivary gland & 14.9 & 24.5 & 1.9 & 2.3 & 21.8 & 30.9 & $\Delta$ & NT & $\Delta:$ Acinar cells \\
\hline \multirow{3}{*}{ Lymphoid system } & Thymus & 8.0 & 7.1 & 0.4 & 0.3 & 13.7 & 8.3 & $\Delta$ & $\Delta$ & $\begin{array}{l}\Delta: \text { Some cells in both } \\
\text { cortex and medulla }\end{array}$ \\
\hline & Spleen & 7.1 & 12.7 & 0.2 & 0.3 & 1.5 & 2.2 & $\Delta$ & $\Delta$ & $\begin{array}{l}\Delta: \text { Some cells in both } \\
\text { red pulp and white pulp }\end{array}$ \\
\hline & Bone marrow & 10.7 & 14.7 & ND & 0.3 & 2.6 & 5.4 & - & - & - \\
\hline \multirow{4}{*}{ Endocrine system } & Adrenal gland & 80.5 & 81.8 & 1.7 & 0.6 & 208.7 & 153.0 & - & NT & - \\
\hline & Pituitary gland & 170.2 & 107.1 & 14.1 & 10.8 & 177.1 & 152.5 & - & NT & - \\
\hline & Thyroid gland & 37.8 & 46.4 & 0.8 & 1.0 & 33.5 & 97.2 & $\Delta$ & NT & $\Delta:$ Follicular cell \\
\hline & Pancreatic islet & NT & NT & NT & NT & NT & NT & - & - & - \\
\hline $\begin{array}{l}\text { Musculoskeletal } \\
\text { system }\end{array}$ & Skeletal muscle & 4.3 & 4.2 & 0.1 & 0.1 & 6.6 & 6.9 & - & - & - \\
\hline \multirow{2}{*}{ Adipose tissue } & $\begin{array}{ll}\text { White adipose } \\
\text { tissue }\end{array}$ & $\mathrm{e}_{35.7}$ & 41.9 & 0.6 & 0.6 & 87.2 & 91.9 & - & - & - \\
\hline & $\begin{array}{l}\text { Brown adipose } \\
\text { tissue }\end{array}$ & $\mathrm{e}_{8.2}$ & 7.6 & 0.2 & 0.2 & 16.8 & 13.6 & - & - & - \\
\hline $\begin{array}{l}\text { Integumentary } \\
\text { system }\end{array}$ & Skin & 28.2 & 29.5 & ND & ND & 10.0 & 10.0 & $\Delta$ & NT & $\Delta:$ Sebocyte \\
\hline \multirow{3}{*}{$\begin{array}{l}\text { Male } \\
\text { reproductive } \\
\text { system }\end{array}$} & Testis & 45.1 & & 7.0 & & 60.1 & & $\begin{array}{l}3+; \\
\Delta\end{array}$ & & $\begin{array}{l}+: \text { Germ cell } \\
\Delta: \text { Leydig cell }\end{array}$ \\
\hline & Seminal vesicle & 115.3 & & 1.5 & & 203.5 & & - & & - \\
\hline & $\begin{array}{l}\text { Coagulating } \\
\text { gland }\end{array}$ & 154.9 & & 5.2 & & 121.6 & & $\Delta$ & & - \\
\hline \multirow{2}{*}{$\begin{array}{l}\text { Female } \\
\text { reproductive } \\
\text { system }\end{array}$} & Ovary & & 137.3 & & 14.3 & & 130.0 & & NT & +: Germ cell \\
\hline & Uterus & & 172.9 & & 1.1 & & 120.5 & & NT & - \\
\hline
\end{tabular}

$\mathrm{ND}=$ not detected. $\mathrm{NT}=$ not tested. 


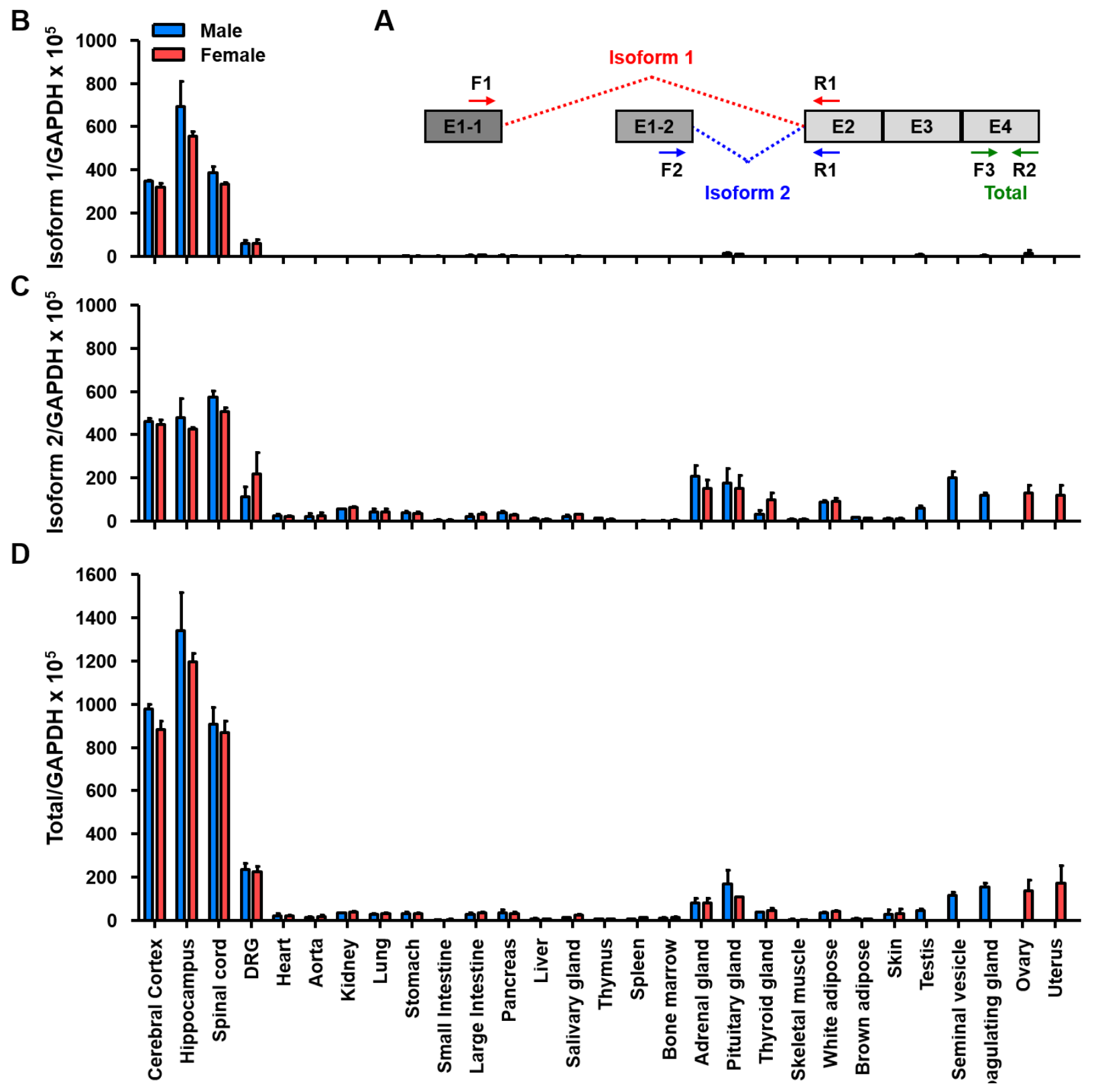

Figure 1. FAM19A5 transcript levels were measured by qRT-PCR. (A) A schematic diagram illustrating the PCR primer locations used to determine the FAM19A5 isoform 1, isoform 2, and total FAM19A5 transcripts. Isoform 1 and isoform 2 differ in the exon 1 sequence (E1-1 for isoform 1 and E1-2 for isoform 2) and share exons 2-4. Dashed lines indicate splicing junctions for isoform 1 (red) and isoform 2 (blue). Isoform 1, isoform 2, and total transcript levels were analyzed using F1-R1, F2-R2, and F3-R3 primer combinations, respectively. (B-D) qRT-PCR analysis of FAM19A5 transcript isoform 1 (B), isoform 2 (C) and total transcript (D) levels in the cortex, hippocampus, spinal cord, DRG, heart, aorta, kidney, lung, stomach, small intestine, large intestine, pancreas, liver, salivary glands, thymus, spleen, bone marrow, adrenal gland, pituitary gland, thyroid gland, skeletal muscle, adipose tissues, skin, testis, seminal vesicle, and coagulating gland. Values are presented as the mean \pm standard error of the mean from three independent experiments. 


\section{FAM19A5 expression in peripheral tissues using FAM19A5-LacZ KI mouse}

To identify cell types that express the FAM19A5 transcript, X-gal staining of tissue from FAM19A5-LacZ KI mice was used ${ }^{5}$. Positive $\mathrm{X}$-gal staining in diverse cell types including neurons, astrocytes, OPCs, and microglia was consistent with the results of single-cell RNAsequencing of mouse and human brains ${ }^{6,7}$. In addition, the X-gal signal intensity was highly correlated with the FAM19A5 transcript levels that were measured with qRT-PCR in an earlier study ${ }^{5}$.

Here, we further identified peripheral tissues that express FAM19A5 using FAM19A5-LacZ knock-in mice. X-gal staining was performed for various peripheral tissues including the heart, aorta, kidneys, lungs, stomach, small intestine, large intestine, pancreas, liver, salivary glands (submandibular, sublingual, and parotid gland), thymus, spleen, bone marrow, adrenal gland, pituitary gland, thyroid gland, skeletal muscle, adipose tissues, skin, testis, seminal vesicle, and coagulating gland (Supplementary Table and Supplementary Figures 1-24). The FAM19A5 promoter-driven $\mathrm{X}$-gal signals were not observed in most tissues. The exceptions to this trend were subsets of cardiac muscle cells, smooth muscle cells or mesenteric plexuses of the gastrointestinal tract tissues, inner cortical cells of X-zone in the adrenal gland, myometrial smooth muscle cells in the uterus, and germ cells in the testis and ovary (Figure 2 and Supplementary Figures 1-24). The X-gal signal intensity observed in these cells was very faint to moderate when compared with the staining in the brain hippocampus (Figure 2). X-gal staining in the white and brown adipose tissues was not detected even though these tissues was reported to express high levels of FAM19A5 ${ }^{3}$. The X-gal signals observed in WT mice were likely due to tissue-specific high endogenous $\beta$-gal expression ${ }^{30-32}$. The endogenous $\beta$-gal-driven $X$-gal positive tissues included the glomeruli and renal tubules in the kidney, individual cells in the gastrointestinal mucosa, alveolar macrophages, respiratory epithelia in the lung, thymus, and spleen immune cells, thyroid follicles, white and brown adipose tissues, sebaceous skin glands in the skin, and the coagulating gland epithelium, leydig cells in the testis, endometrial glandular epithelium in the uterus, and granulosa and lutein cells in the ovary.(Figure 2 and Supplementary Table and Supplementary Figures 1-24). 

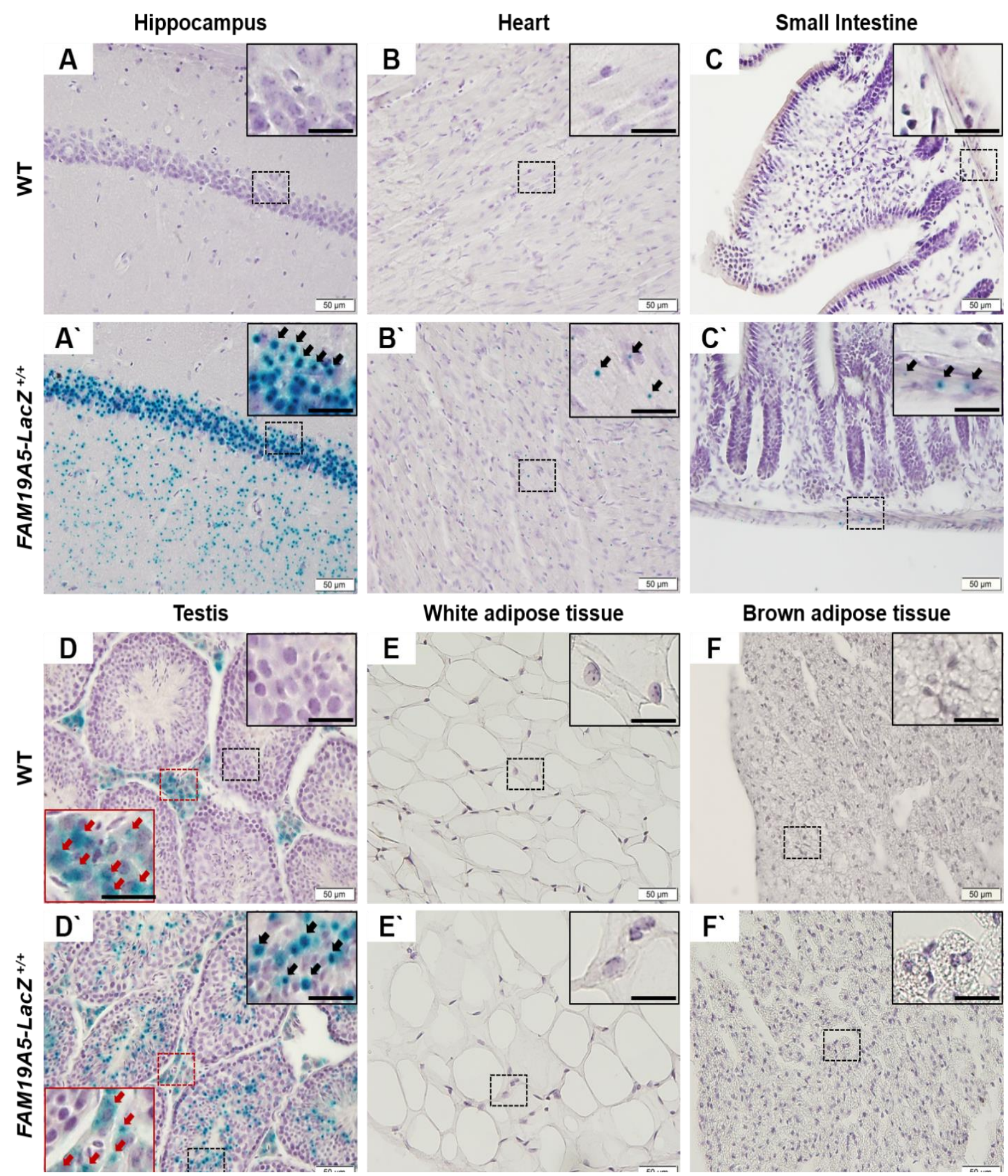

Figure 2. X-gal staining of peripheral tissues from wild-type and FAM19A5-LacZ knock-in (+/+) mice. (A-F) Cryosections were stained with $\mathrm{X}$-gal solution and counter-stained with hematoxylin. Representative light photomicrographs of the brain hippocampus (A, A'), heart (B, B'), small intestine (C, C'), testis (D, D'), white adipose tissue (E, E'), and brown adipose tissue (F, F') from wild-type (A-F) and FAM19A5-LacZ+/+ (A'-F') mice. Images in the dashed boxes were magnified in the upper right. Dot-shaped blue precipitates were only present in the FAM19A5LacZ+/+ samples that contain black arrows (A', B' C' and D'). Dispersed precipitates were observed in both WT and FAM19A5-LacZ+/+ samples and are indicated by red arrows (D and D'). Scale bars in the inset represent $20 \mu \mathrm{m}$. 


\section{FAM19A5 protein levels in peripheral tissues}

FAM19A5 KO mice were generated with the CRISPR/Cas9 system (Figure 3A and B) and their FAM19A5 transcript and protein levels were measured (Figure 3C, D, and E). Analysis with qRT-PCR indicated that FAM19A5 transcripts for both isoforms 1 and 2 were not detectable in brain tissue from the FAM19A5 KO mice (Figure 3C). In contrast, Western blotting of WT brain extracts indicated the presence of both glycosylated and non-glycosylated FAM19A5. After treating the brain extracts with PNGase, which is a deglycosylation enzyme, the intensity of the band corresponding to glycosylated FAM19A5 greatly decreased. Concurrently, the intensity of the band corresponding to non-glycosylated FAM19A5 increased. Neither glycosylated nor nonglycosylated forms of FAM19A5 protein were observed in the brain extracts from FAM19A5 KO mice (Figure 3D). Next, we measured FAM19A5 protein levels in white and brown adipose tissues because FAM19A5 expression patterns in these tissues are not well-defined ${ }^{3}$. We also measured FAM19A5 levels in the testis and ovary because they exhibited moderate levels of FAM19A5 transcript. All of the peripheral tissues exhibited FAM19A5 protein levels that were not detectable by Western blotting, which is correlated with the measured FAM19A5 transcript levels (Figure 3E).

A

B
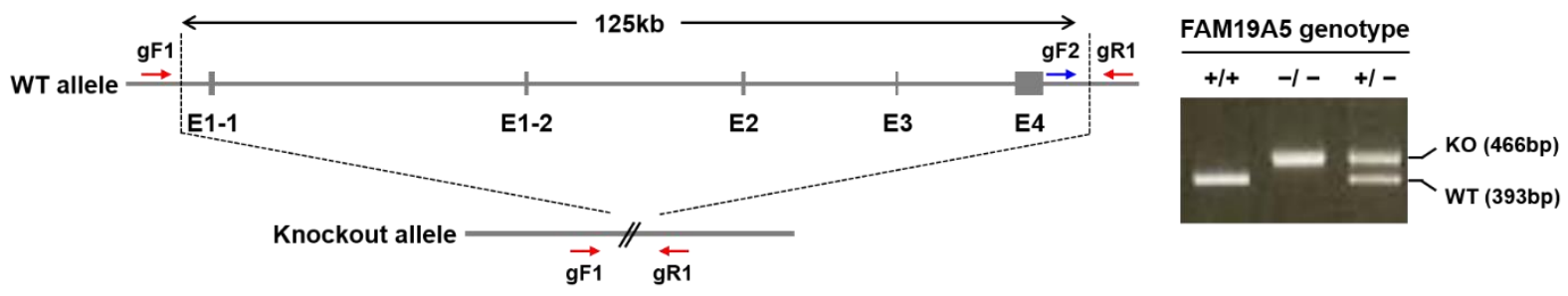

C

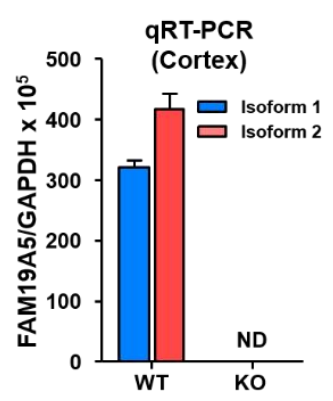

D

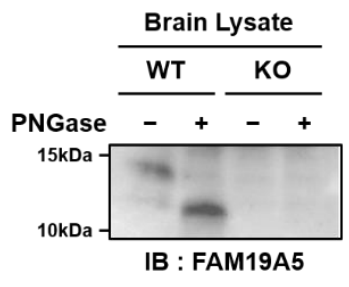

E

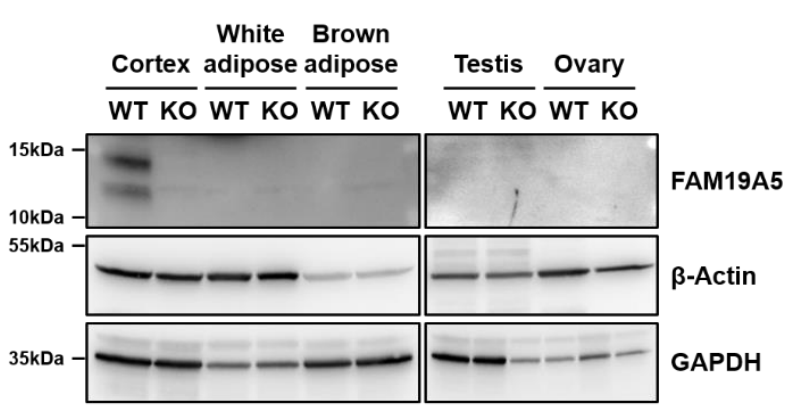

Figure 3. FAM19A5 protein levels in wild-type and FAM19A5 KO mice. (A) A schematic diagram illustrating the genome structures of wild-type (WT) and FAM19A5 knock-out (KO) alleles. The FAM19A5 gene from exon 1-1 (E1-1) to exon 4 (E4) was removed using the CRISPR/Cas9 system. PCR primer locations to determine the WT (gF1$\mathrm{gR} 1)$ and $\mathrm{KO}(\mathrm{gF} 2-\mathrm{gR} 1)$ alleles are indicated. (B) Genotyping of WT (+/+), heterozygous (+/-), and homozygous (-/) FAM19A5 KO mice using genomic DNA. (C) qRT-PCR analysis of FAM19A5 transcript isoform 1 (Iso 1) and isoform 2 (Iso 2) in the cortex of WT and FAM19A5 KO (-/-) mice. (D) Western blot analysis for FAM19A5 proteins extracted from brains of WT and FAM19A5 KO (-/-) mice. The protein samples were treated with PNGase, a deglycosylation enzyme to determine the presence of glycosylated forms of FAM19A5 protein. (E) Western blotting to investigate FAM19A5 protein levels in white and brown adipose tissues, testis, and ovaries of WT and FAM19A5 $\mathrm{KO}(-/-)$ mice. $\beta$-actin and GAPDH protein were used as internal Western blot controls. 


\section{FAM19A5 does not interact with S1PR2}

The previous study reported that FAM19A5 can regulate blood vessel smooth muscle function by interacting with the S1PR2 ${ }^{3}$. We first investigated whether FAM19A5 elicited S1PR2mediated G-protein signaling using an SRE-luc assay system that was coupled to a HEK293-G $\mathrm{G}_{\mathrm{qi}}$ stable cell line ${ }^{27}$. Treatment with sphingosine-1 phosphate (S1P), a natural agonist for S1PR2, for $6 \mathrm{~h}$ substantially increased SRE-luc activity while FAM19A5 failed to show an effect (Figure 4A). These data indicated that FAM19A5 protein cannot induce G-protein-mediated signal transduction in S1PR2-expressing cells. Because some biased agonists induce $\beta$-arrestin recruitment to SIPR2 independent of G-protein mediated signaling ${ }^{27}$, we explored whether FAM19A5 increased the interaction between S1PR2 and $\beta$-arrestin with the NanoLuc luciferase complementation assay $^{28,29}$. S1P induced an immediate increase in luciferase activity, indicating an interaction between S1PR2 and $\beta$-arrestin. FAM19A5 has no effect (Figure 4B). Next, we investigated the effect of FAM19A5 on the internalization of S1PR2 using HEK293 cells that expressed a S1PR2GFP construct. Confocal microscopy images indicated that S1PR2 is primarily localized to the plasma membrane in the absence of ligand treatment. After treatment with S1P for 30 min, the cellular internalization of S1PR2-GFP increased. However, treatment with FAM19A5 did not result in S1PR2-GFP internalization. Furthermore, FAM19A5-Cy3 was internalized regardless of S1PR2 expression (Figure 4C). Collectively, these data indicate that FAM19A5 cannot induce either $\beta$-arrestin recruitment to S1PR2 or ligand-stimulated internalization of S1PR2.

A

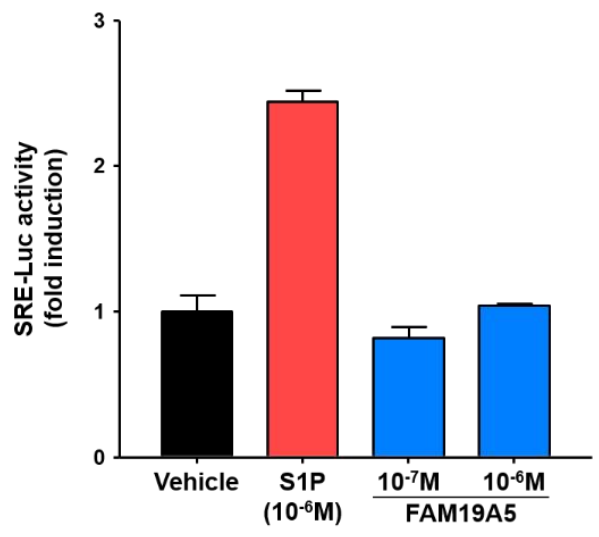

B

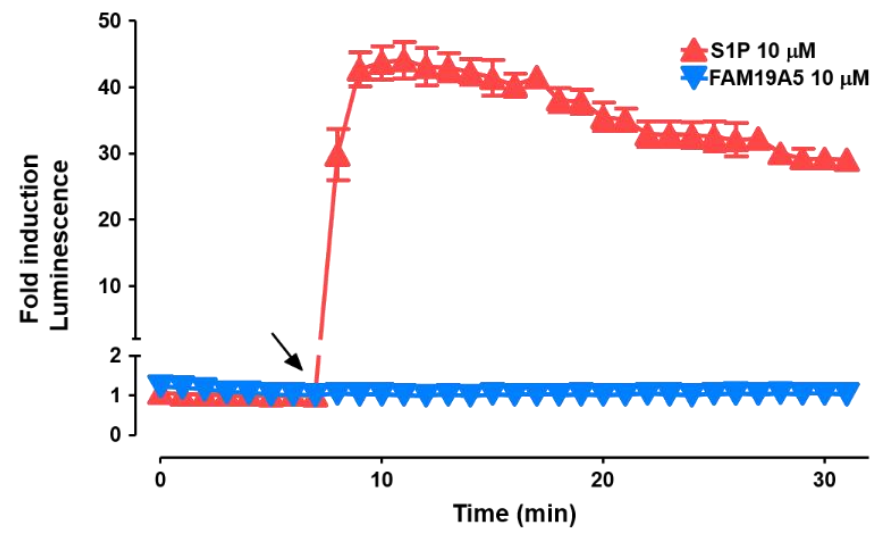

C

S1PR2-GFP

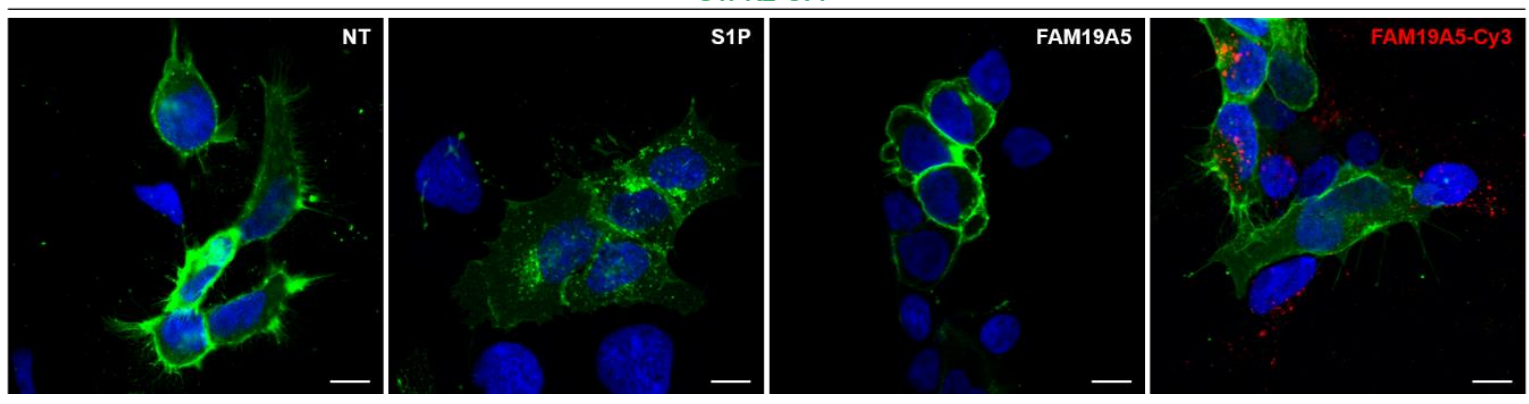

Figure 4. FAM19A5 protein did not interact with S1PR2. (A) An SRE-luc reporter assay was used to determine S1PR2 receptor activation in response to S1P and FAM19A5. SRE-luc reporter and S1PR2 genes were co-transfected 
into HEK293 cells that stably expressed Gqi protein. Cells in serum-free medium were then treated with both S1P and FAM19A5 for $6 \mathrm{~h}$ and subjected to a luciferase assay system. (B) Nano-luc reporter assay for $\beta$-arrestin recruitment to S1PR2. S1PR2-LgBit and $\beta$-arrestin-SmBit constructs were co-transfected into HEK293 cells. Under a live cell system, luminescence was determined before and after treatment with S1P and FAM19A5. Data are presented as the mean \pm standard error of the mean from three independent experiments. (C) Internalization of S1PR2 in response to S1P and FAM19A5. HEK293 cells were transfected with a S1PR2-GFP construct. Cells were cultured under serumfree conditions for $16 \mathrm{hr}$ and then treated with S1P, naïve FAM19A5, and FAM19A5-Cy3 for 30 min. Cellular locations of S1PR2-GFP in the presence of the ligands were determined using a confocal microscope. Scale bar represents $10 \mu \mathrm{m}$.

\section{FAM19A5 internalizes into HEK293 cells in a serum- and extracellular matrix-dependent manner}

We examined whether FAM19A5-A488 and non-conjugated FAM19A5 could be internalized into HEK293 cells. The FAM19A5-A488 was readily internalized into the cells (Figure 5A) and once internalized, immunocytochemistry revealed that FAM19A5-A488 colocalized with a Cy3-conjugated N-A5-Ab (Figure 5A). Immunocytochemistry also indicated that a non-conjugated native form of FAM19A5 internalized into HEK293 cells (Data not shown). FAM19A5 internalization was completely inhibited by pretreatment with dynasore, pitstop, and chlorpromazine, which are blockers for clathrin-dependent internalization (Figure 5B and data not shown for pitstop and chrlorpromazine). Notably, FAM19A5 internalization was unaffected by filipin and nystatin, which are blockers for caveolin-dependent internalization (Data not shown). Thus, FAM19A5 may interact with a cell surface receptor prior to receptor-mediated internalization through a dynamin/clathrin-dependent manner. FAM19A5 internalization was significantly attenuated by high serum concentrations (10\%) (Figure 5C) and also by pretreatment with extracellular matrix (ECM) molecules including fibronectin (FN), fibrinogen, and laminin (Figure 5C). These inhibition patterns suggest that FAM19A5 internalization is likely mediated by a membrane bound-cell surface molecule that interacts with ECM and/or serum components. FAM19A5 binding and internalization into HEK293 cells was also investigated with FACS analysis (Figure 5D). FAM19A5-A488 bound to HEK293 cells (Figure 5D), and increased binding was attenuated by pretreatment with naïve FAM19A5. Furthermore, pretreatment with FN decreased FAM19A5-A488 binding to HEK293 cells, indicating that FN can compete with FAM19A5 (Figure 5D). 
A

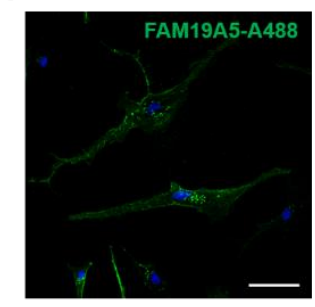

C

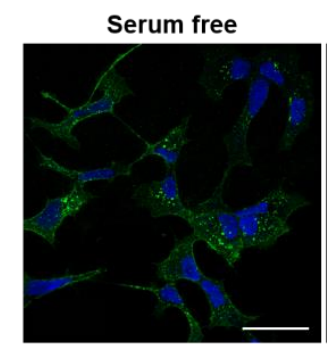

D

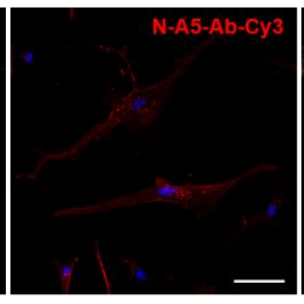

$10 \%$ serum

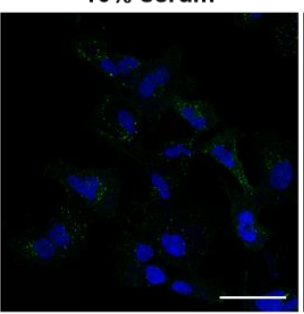

FAM19A5-A488

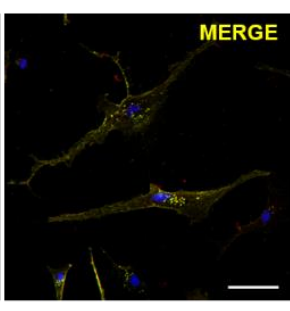

Fibronectin

B
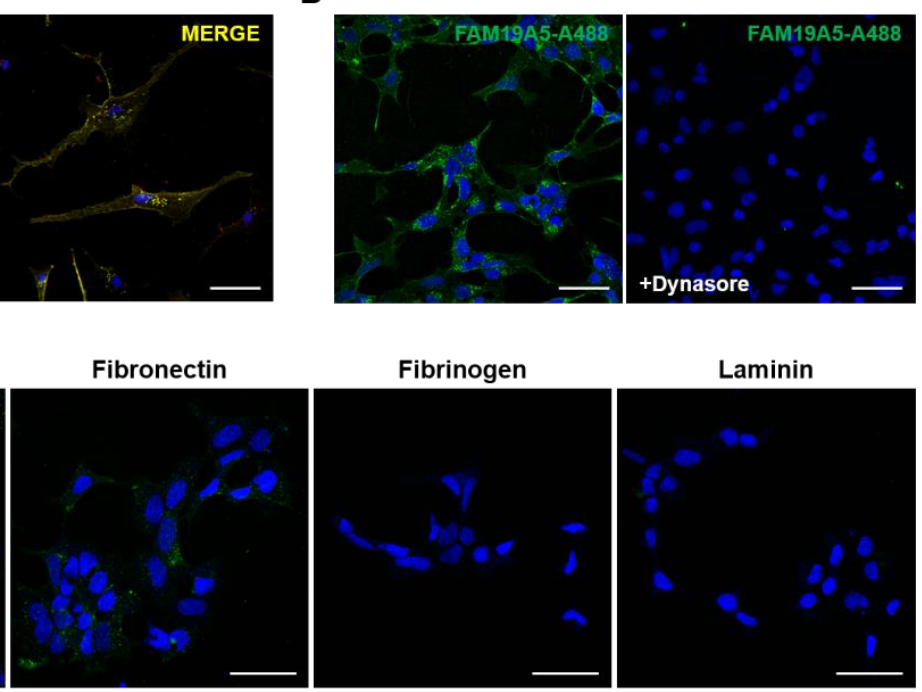

FAM19A5-A488 + FAM19A5

FAM19A5-A488
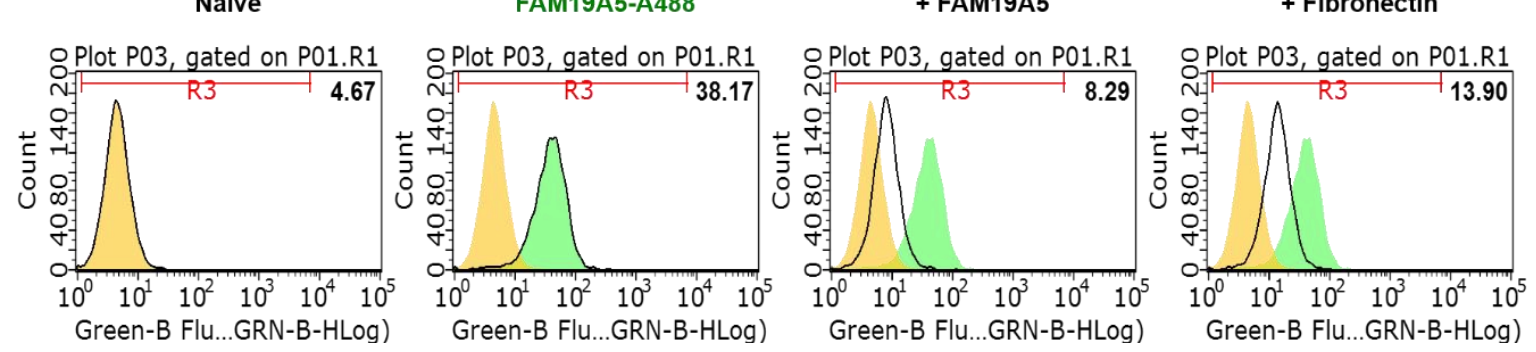

Figure 5. FAM19A5 was internalized in an extracellular matrix-dependent manner. (A) Internalization of FAM19A5-A488. All internalization assays were performed in serum-free conditions. HEK293 cells were treated with FAM19A5-A488 for 30 min and immunostained with N-A5-Ab-Cy3. (B) Clathrin-dependent internalization of FAM19A5. HEK293 cells were treated with FAM19A5-A488 in the presence or absence of $80 \mu \mathrm{M}$ dynasore. (C) Serum- and ECM-dependent internalization of FAM19A5-A488. FAM19A5-A488 internalization was measured in the presence of $10 \%$ fetal bovine serum or after pretreatment with $200 \mu \mathrm{g} / \mathrm{ml}$ of fibronectin, fibrinogen, and laminin. (D) FAM19A5 binding to HEK293 cells was measured using flow cytometry. HEK293 cells were treated with FAM19A5-A488 $(2 \mu \mathrm{g})$ in the presence of naïve FAM19A5 or fibronectin $(20 \mu \mathrm{g})$.

\section{Discussion}

Quantitative levels of FAM19A5 total transcripts, isoform 1, and isoform 2 were investigated in a wide variety of peripheral tissues and compared to levels of specific brain regions. In general, FAM19A5 transcript levels in the peripheral tissues were very low when compared with brain tissue levels. We hypothesize that isoform 2 is the major form of FAM19A5 in peripheral tissues and that isoform 1 is minimally expressed in these tissues. In contrast, the brain tissues expressed isoforms 1 and 2 equally. Isoform 1 produces a mature secretory protein ${ }^{3}$ and isoform 2 primarily produces a plasma membrane-bound protein ${ }^{4}$. Isoform 2 also produces small 
quantities of the secretory protein ${ }^{3}$. Thus, the soluble secretory form of FAM19A5 is produced at lower quantities in the peripheral tissues than in the brain.

Similar to the low levels of FAM19A5 transcripts that were measured in the peripheral tissues, FAM19A5 promoter-driven X-gal signals were also very faint or negligible for peripheral tissues when compared to the signal in the brain. Only a few samples exhibited faint to moderate $\mathrm{X}$-gal signals. These cells included cardiac muscle cells, gastrointestinal cells (likely smooth muscle cells or mesenteric plexuses) in the muscularis externa, and germ cells in the testis and ovary. We did not detect X-gal signals in any other tissues including white adipose tissue and the thyroid and adrenal glands. Because both the X-gal intensity and the total transcript levels were very low in the peripheral tissues when compared to the brain, we conclude that the levels of FAM19A5 protein produced in these cells/tissues are likely very low. The functional relevance of these low-level proteins in the peripheral tissues needs to be investigated further.

It is intriguing that no FAM19A5 promoter-driven X-gal signals were observed in adipose tissue cells, even though these tissues cells are reported to produce significantly high levels of both FAM19A5 transcripts and protein ${ }^{3}$. Furthermore, our qRT-PCR results demonstrated that the transcript levels measured in white and brown adipose tissues were significantly lower than brain tissue levels. Our data is in agreement with The Human Protein Atlas Database (https://www.proteinatlas.org) which includes three independent datasets (HPA, https://www.proteinatlas.org/; GTEx, https://gtexportal.org/; and FANTOM5, http://fantom.gsc.riken.jp/5/) that show FAM19A5 transcript levels in human adipose tissue is approximately $1 / 100$ to $1 / 50$ the amount found in human brain tissue $\mathrm{e}^{33-35}$. These datasets also show extremely low levels of FAM19A5 transcripts in peripheral tissues and low-to-moderate expression levels in female and male reproductive tissues. Western blotting analysis for FAM19A5 expression in WT and FAM19A5 KO mice is also in agreement with the available data. FAM19A5 protein in adipose and reproductive tissues was below detectable levels, but brain tissue expression was high.

We were unable to observe X-gal signals in the bone marrow, thymus, and spleen, which are blood cell-producing organs ${ }^{36}$. Thus, the low levels of FAM19A5 transcripts in peripheral tissues raise questions about the origin of FAM19A5 in the blood. Recently, blood FAM19A5 levels were measured in human ${ }^{9}$ and mouse samples ${ }^{3}$. The blood levels of FAM19A5 that were measured by ELISA ranged from $100 \mathrm{pg} / \mathrm{ml}$ for human samples ${ }^{9}$ to $400 \mathrm{ng} / \mathrm{ml}$ for mouse samples ${ }^{3}$. In addition, a proteomic approach revealed that FAM19A5 was a novel serum biomarker that could be used to differentiate cholangiocarcinoma from benign biliary tract diseases ${ }^{37}$. There are many possible sources of FAM19A5 in the blood. FAM19A5 transcript levels are up-regulated under certain pathological conditions. For example, traumatic brain injury increased FAM19A5 transcription in a subset of neurons found in the injury penumbra and a subset of OPCs found in the corpus callosum ${ }^{5}$. In this case, FAM19A5 produced in the brain crossed over the blood-brain barrier to increase blood levels of FAM19A5. FAM19A5 was also expressed in a subpopulation of blood vessel endothelial cells and pericytes ${ }^{5}$; therefore, these cells could be another possible 
source of blood FAM19A5 during disease. In the context of tumor cells, The Human Protein Atlas Database (https://www.proteinatlas.org) reports high FAM19A5 transcript levels in glioma, pancreatic cancer, and melanoma ${ }^{22}$. These data suggest that tumor cells themselves can be a source of blood FAM19A5.

In contrast to the previously published study, our data showed that FAM19A5 does not interact with S1PR2 to induce receptor-mediated G-protein activation and $\beta$-arrestin recruitment that leads to receptor internalization. We showed that FAM19A5 can bind to and be internalized by HEK293 cells independent of S1PR2. Furthermore, the binding and internalization events were inhibited by pretreatment with ECM molecules. FAM19A5 interacts with ECM molecules in either a competitive or antagonistic manner, which can contribute to functional modulation of the ECM under pathological conditions.

In summary, FAM19A5 transcription and protein levels in peripheral tissues were significantly lower than brain tissue levels. A subset of muscle cells in the heart, GI tract, and testis was FAM19A5 promoter-driven X-gal positive. However, the cells in most peripheral tissues including adipose tissues, bone marrow, the thymus, and the spleen were X-gal negative. This study does not exclude the possibility that FAM19A5 transcript/protein levels in the periphery tissues can increase under pathological conditions, which are already suggested by GWAS and RNA-seq analyses that revealed associations between the FAM19A5 gene and peripheral disease and tumorigenesis. Therefore, this study determined basal levels of FAM19A5 transcripts and protein in peripheral tissues, providing the foundational basis to investigate peripheral FAM19A5 function under pathophysiological conditions.

\section{Author contributions}

E-H.C. and H.K. performed experiments, analyzed the results, and wrote the manuscript; E.B.C., S.A., H.J.Y, Y.J., Y.L, M.L., N.H., and S.O. designed and performed experiments, analyzed the results, and wrote the manuscript; W.S.L., W.K. and J.K.L. wrote the manuscript; J.Y.S. formulated the study, designed the experiments, and wrote the manuscript.

\section{Sources of Funding}

This work was supported by grants from the Research Programs (2017R1A2B4006975) of the National Research Foundation of Korea (NRF) funded by the Ministry of Science, ICT, and Future Planning and from the Industrial Technology Innovation Program (10081300) funded by the Ministry of Trade, Industry \& Energy, Korea. 


\section{Disclosures}

The authors H.K., E-H.C., E.B.C., Y.J., Y.L., M.L., N.H., S.O., J.K.L., and W.S.L. are the employees of Neuracle Science Co., Ltd. The author J.Y.S. is the shareholder of Neuracle Science Co., Ltd. All other authors declare no competing interests.

\section{Data Availability Statement}

All the data generated for this study are included in the manuscript and the supplementary information. The raw data supporting this manuscript are available upon request.

\section{References}

1. Tom Tang Y, Emtage P, Funk WD, Hu T, Arterburn M, Park EE., Rupp F. TAFA: a novel secreted family with conserved cysteine residues and restricted expression in the brain. Genomics. 2004;83(4):727-734.

2. Zerbino DR, Achuthan P, Akanni W, Amode MR, Barrell D, Bhai J, Billis K, Cummins C, Gall A, Girón CG, Gil L, Gordon L, Haggerty L, Haskell E, Hourlier T, et al. Ensembl 2018. Nucleic acids research. 2018;46(D1):D754-D761.

3. Wang Y, Chen D, Zhang Y, Wang P, Zheng C, Zhang S, Yu B, Zhang L, Zhao G, Ma B, Cai Z, Xie N, Huang S, Liu Z, Mo X, et al. Novel adipokine, FAM19A5, inhibits neointima formation after injury through Sphingosine-1-Phosphate Receptor 2. Circulation. 2018;138(1):48-63.

4. Thul PJ, Åkesson L, Wiking M, Mahdessian D, Geladaki A, Ait Blal H, Alm T, Asplund A, Björk L, Breckels LM, Bäckström A, Danielsson F, Fagerberg L, Fall J, Gatto L, et al. A subcellular map of the human proteome. Science (New York, N.Y.). 2017;356(6340):eaal3321.

5. Shahapal A, Cho EB, Yong HJ, Jeong I, Kwak H, Lee JK, Kim W, Kim B, Park H-C, Lee WS, Kim H, Hwang J-I, Seong JY. FAM19A5 expression during embryogenesis and in the adult traumatic brain of FAM19A5-LacZ knock-in mice. Frontiers in Neuroscience. 2019;13:Article 917.

6. Zhang Y, Chen K, Sloan SA, Bennett ML, Scholze AR, O'Keeffe S, Phatnani HP, Guarnieri P, Caneda C, Ruderisch N, Deng S, Liddelow SA, Zhang C, Daneman R, Maniatis T, et al. An RNA-sequencing transcriptome and splicing database of glia, 
neurons, and vascular cells of the cerebral cortex. The Journal of neuroscience : the official journal of the Society for Neuroscience. 2014;34(36):11929-47.

7. Zhang Y, Sloan SA, Clarke LE, Caneda C, Plaza CA, Blumenthal PD, Vogel H, Steinberg GK, Edwards MSB, Li G, Duncan JA, Cheshier SH, Shuer LM, Chang EF, Grant GA, et al. Purification and characterization of progenitor and mature human astrocytes reveals transcriptional and functional differences with mouse. Neuron. 2016;89(1):37-53.

8. Park MY, Kim HS, Lee M, Park B, Lee HY, Cho EB, Seong JY, Bae YS. FAM19A5, a brain-specific chemokine, inhibits RANKL-induced osteoclast formation through formyl peptide receptor 2. Scientific Reports. 2017;7(1):15575.

9. Lee Y Bin, Hwang HJ, Kim JA, Hwang SY, Roh E, Hong SH, Choi KM, Baik SH, Yoo HJ. Association of serum FAM19A5 with metabolic and vascular risk factors in human subjects with or without type 2 diabetes. Diabetes and Vascular Disease Research. 2019:147916411986074.

10. Petryszak R, Keays M, Tang YA, Fonseca NA, Barrera E, Burdett T, Füllgrabe A, Fuentes AMP, Jupp S, Koskinen S, Mannion O, Huerta L, Megy K, Snow C, Williams E, et al. Expression Atlas update - An integrated database of gene and protein expression in humans, animals and plants. Nucleic Acids Research. 2016;44(D1):D746-D752.

11. Herold C, Hooli B V, Mullin K, Liu T, Roehr JT, Mattheisen M, Parrado AR, Bertram L, Lange C, Tanzi RE. Family-based association analyses of imputed genotypes reveal genome-wide significant association of Alzheimer's disease with OSBPL6, PTPRG, and PDCL3. Molecular psychiatry. 2016;21(11):1608-1612.

12. Mez J, Chung J, Jun G, Kriegel J, Bourlas AP, Sherva R, Logue MW, Barnes LL, Bennett DA, Buxbaum JD, Byrd GS, Crane PK, Ertekin-Taner N, Evans D, Fallin MD, et al. Two novel loci, COBL and SLC10A2, for Alzheimer's disease in African Americans. Alzheimer's \& dementia : the journal of the Alzheimer's Association. 2017;13(2):119129.

13. Yu H, Yan H, Wang L, Li J, Tan L, Deng W, Chen Q, Yang G, Zhang F, Lu T, Yang J, Li K, Lv L, Tan Q, Zhang H, et al. Five novel loci associated with antipsychotic treatment response in patients with schizophrenia: a genome-wide association study. The lancet. Psychiatry. 2018;5(4):327-338.

14. Li Q, Wineinger NE, Fu D-J, Libiger O, Alphs L, Savitz A, Gopal S, Cohen N, Schork NJ. Genome-wide association study of paliperidone efficacy. Pharmacogenetics and genomics. 2017;27(1):7-18.

15. Winham SJ, Cuellar-Barboza AB, Oliveros A, McElroy SL, Crow S, Colby C, Choi D-S, 
Chauhan M, Frye M, Biernacka JM. Genome-wide association study of bipolar disorder accounting for effect of body mass index identifies a new risk allele in TCF7L2. Molecular psychiatry. 2014;19(9):1010-6.

16. Wu C, Miao X, Huang L, Che X, Jiang G, Yu D, Yang X, Cao G, Hu Z, Zhou Y, Zuo C, Wang C, Zhang X, Zhou Y, Yu X, et al. Genome-wide association study identifies five loci associated with susceptibility to pancreatic cancer in Chinese populations. Nature genetics. 2011;44(1):62-6.

17. De Vivo I, Prescott J, Setiawan VW, Olson SH, Wentzensen N, Attia J, Black A, Brinton L, Chen C, Chen C, Cook LS, Crous-Bou M, Doherty J, Dunning AM, Easton DF, et al. Genome-wide association study of endometrial cancer in E2C2. Human Genetics. 2014;133(2):211-224.

18. Carvalho-Silva D, Pierleoni A, Pignatelli M, Ong CK, Fumis L, Karamanis N, Carmona M, Faulconbridge A, Hercules A, McAuley E, Miranda A, Peat G, Spitzer M, Barrett J, Hulcoop DG, et al. Open Targets Platform: New developments and updates two years on. Nucleic Acids Research. 2019;47(D1):D1056-D1065.

19. Kashevarova AA, Belyaeva EO, Nikonov AM, Plotnikova O V., Skryabin NA, Nikitina T V., Vasilyev SA, Yakovleva YS, Babushkina NP, Tolmacheva EN, Lopatkina ME, Savchenko RR, Nazarenko LP, Lebedev IN. Compound phenotype in a girl with r(22), concomitant microdeletion 22q13.32-q13.33 and mosaic monosomy 22. Molecular Cytogenetics. 2018;11(1):26.

20. Inan C, Sayin NC, Gurkan H, Atli E, Gursoy Erzincan S, Uzun I, Sutcu H, Dogan S, Ikbal Atli E, Varol F. Schizencephaly accompanied by occipital encephalocele and deletion of chromosome 22q13.32: a case report. Fetal and Pediatric Pathology. 2019:1-7.

21. Díaz De Ståhl T, Hartmann C, De Bustos C, Piotrowski A, Benetkiewicz M, Mantripragada KK, Tykwinski T, Von Deimling A, Dumanski JP. Chromosome 22 tilingpath array-CGH analysis identifies germ-line- and tumor-specific aberrations in patients with glioblastoma multiforme. Genes Chromosomes and Cancer. 2005;44(2):161-169.

22. Uhlen M, Zhang C, Lee S, Sjöstedt E, Fagerberg L, Bidkhori G, Benfeitas R, Arif M, Liu Z, Edfors F, Sanli K, von Feilitzen K, Oksvold P, Lundberg E, Hober S, et al. A pathology atlas of the human cancer transcriptome. Science (New York, N.Y.).

2017;357(6352):eaan2507.

23. Grossman RL, Heath AP, Ferretti V, Varmus HE, Lowy DR, Kibbe WA, Staudt LM. Toward a shared vision for cancer genomic data. New England Journal of Medicine. 2016;375(12):1109-1112. 
24. Lee JH, Park J-H, Nam T-W, Seo S-M, Kim J-Y, Lee H-K, Han JH, Park SY, Choi Y-K, Lee H-W. Differences between immunodeficient mice generated by classical gene targeting and CRISPR/Cas9-mediated gene knockout. Transgenic Research. 2018;27(3):241-251.

25. Mountford P, Zevnik B, Düwel A, Nichols J, Li M, Dani C, Robertson M, Chambers I, Smith A. Dicistronic targeting constructs: reporters and modifiers of mammalian gene expression. Proceedings of the National Academy of Sciences. 1994;91(10):4303-4307.

26. Conklin BR, Farfel Z, Lustig KD, Julius D, Bourne HR. Substitution of three amino acids

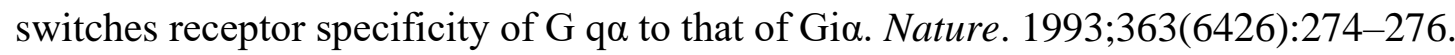

27. Kim DK, Yun S, Son GH, Hwang JI, Park CR, Kim J Il, Kim K, Vaudry H, Seong JY. Coevolution of the spexin/galanin/kisspeptin family: Spexin activates galanin receptor type II and III. Endocrinology. 2014;155(5):1864-1873.

28. Reyes-Alcaraz A, Lee Y-N, Yun S, Hwang J-I, Seong JY. Conformational signatures in $\beta$ arrestin2 reveal natural biased agonism at a G-protein-coupled receptor. Communications Biology. 2018;1(1):128.

29. Reyes-Alcaraz A, Lee Y-N, Yun S, Hwang J-I, Seong JY. Monitoring GPCR-betaarrestin1/2 Interactions in Real Time Living Systems to Accelerate Drug Discovery. Journal of Visualized Experiments. 2019;(148).

30. Conchie J, Findlay J, Levvy GA. Mammalian glycosidases; distribution in the body. The Biochemical journal. 1959;71(2):318-25.

31. Johnson WG, Hong JL, Knights SM. Variation in ten lysosomal hydrolase enzyme activities in inbred mouse strains. Biochemical genetics. 1986;24(11-12):891-909.

32. Trifonov S, Yamashita Y, Kase M, Maruyama M, Sugimoto T. Overview and assessment of the histochemical methods and reagents for the detection of $\beta$-galactosidase activity in transgenic animals. Anatomical Science International. 2016;91(1):56-67.

33. Uhlen M, Fagerberg L, Hallstrom BM, Lindskog C, Oksvold P, Mardinoglu A, Sivertsson A, Kampf C, Sjostedt E, Asplund A, Olsson I, Edlund K, Lundberg E, Navani S, Szigyarto CA-K, et al. Tissue-based map of the human proteome. Science. 2015;347(6220):1260419-1260419.

34. The GTEx Consortium. Human genomics. The Genotype-Tissue Expression (GTEx) pilot analysis: multitissue gene regulation in humans. Science (New York, N.Y.). 2015;348(6235):648-660. 
35. Lizio M, Harshbarger J, Shimoji H, Severin J, Kasukawa T, Sahin S, Abugessaisa I, Fukuda S, Hori F, Ishikawa-Kato S, Mungall CJ, Arner E, Baillie J, Bertin N, Bono H, et al. Gateways to the FANTOM5 promoter level mammalian expression atlas. Genome Biology. 2015;16(1):22.

36. Müller AM, Medvinsky A, Strouboulis J, Grosveld F, Dzierzakt E. Development of hematopoietic stem cell activity in the mouse embryo. Immunity. 1994;1(4):291-301.

37. Janvilisri T, Leelawat K, Roytrakul S, Paemanee A, Tohtong R. Novel serum biomarkers to differentiate cholangiocarcinoma from benign biliary tract diseases using a proteomic approach. Disease Markers. 2015;2015:105358. 